\title{
How Estimates Of Share Of Voice (SOV) Affect Advertising Budgeting Decisions
}

Thomas W. Whipple, (E-mail: t.whipple@csuohio.edu), Cleveland State University Lou Walcer, (E-mail: lwalcer@mediconcepts.com), Mediconcepts

\begin{abstract}
An advertising budgeting procedure that compares share of voice to share of market for a brand and its largest competitor has been employed in established consumer packaged goods categories. This study implements similar procedures in a capital goods category, namely medical imaging equipment. Alternative estimates of share of voice and their impact on advertising budgeting decisions are considered. Advertising budgeting recommendations are presented.
\end{abstract}

\section{Introduction}

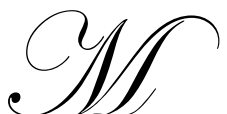

arketers may have lost sight of the connection between advertising spending and share of market (SOM). Although advertising models, such as ADBUDG, have related market share to advertising expenditures for decades, advertising's share of voice (SOV) has lost favor to minimum effective frequency and effective reach measures in advertising budgeting decisions. The reasons for this shift in focus may be due to measurement problems as well as to issues attributed to differences between academic models and industry practice. However, there are strategic-oriented advertising budgeting models that may have practical significance if SOV measurement issues can be resolved and if SOV estimates are incorporated into market share models.

This study was designed to assess the relative share of advertising activity - its "Share of Voice"-in medical equipment product market sectors in which four major companies have serious interests and ongoing marketing communications programs. A strategic model is introduced that utilizes relative advertising spending and market positions to assess past budgeting emphasis and to recommend the focus of future advertising budgets.

\section{Literature}

Peter Turk's (1988) report on the use of effective frequency by ad agency media departments concluded that, compared to other controllable planning dimensions (e.g., reach), effective frequency was considered substantially superior. However, for less controllable factors (e.g., clutter and share of voice), effective frequency was significantly preferred over clutter, but only slightly better than share of voice. These findings underscore that SOV deserves a closer examination in media planning.

SOV explains advertising recall and intent to purchase better than the effective frequency concept. SOV is more influential than GRP weight in determining brand recall or purchase intent for low involvement decisions and mediates the effect of low frequency. Implementing a SOV strategy depends on assessing the past and guessing the future. Since history repeats itself and the consumer base evolves slowly, it is suggested that media planners look beyond frequency distributions to analyze the competition before finalizing a media plan (Kelly, 1985).

SOV is really the total percentage that a brand possesses of a particular audience that is being targeted by that brand (Knight). However, for practical measurement purposes, SOV is a measure of the relative share of the advertising dollars spent to reach specific audiences targeted by a brand. Conventional wisdom suggests that the market leader's SOV can be less than its SOM because the leader enjoys a scale advantage. Other players in the market, to maintain a SOV close to that of the leader, are forced to outspend the leader relative to their market shares. This relative SOV logic does not extend to ad spending for new or highly differentiated products. 
However, very few companies determine advertising budgets on the basis of share of voice. If a company did, it should conclude that rather than challenging competitors in markets where its brand is weak and they are the leaders, as is commonly the case, the company does best by targeting markets where competitors are under spending (Schroer, 1990). In terms of share of voice, some companies are "profit takers" (SOV $<\mathrm{SOM})$ and others, "investors" (SOV $>\mathrm{SOM}$ ). The rationale for calculating advertising intensity by SOV/SOM is based on the assumption that the cost structure of one brand in a market tends to be similar to that of any other (Jones, 1990). And during poor economic times, similar to what companies have faced the last few years, maintaining or increasing ad spending achieves a higher SOV at a lower cost than when the market is growing, if competitors retrench. Implementing such a strategy resulted in substantial increases in market share and profits during economic recovery according to analysis of PIMS data (Findlay).

One model that depends upon SOV and SOM estimates for advertising budgeting is Schroer's (1990) model. Rossiter and Percy (1997, p. 42) use his model to explain recommended established-brand spending strategies (Figure 1). This model assumes a mature product category and has been applied to budgeting recommendations for marketers of multi-regional, consumer package goods.

\section{Research Design and Methodology}

This study was designed to address the particular aspect of the "reach/seen" question by assessing SOV for Brand C and its three principal competitors (Brands A, B, and D) in three defined oligopolistic product categories, coded as categories 1,2, and 3. The methodology for this study was to take a snapshot of all advertising activity observed in three respective imaging marketplaces during a twelve-month study time frame of October 2002 through September 2003. The snapshot was obtained by collecting data from advertisements placed in a variety of relevant journals during the study time frame. All journals currently in Brand C's media schedule were included, as well as a few others in its competitors' media schedules. Two coders collected 20 journals from the current loose and recently bound medical periodicals collections of nine regional libraries, which included libraries of county, state, and private colleges and universities; medical libraries; hospital libraries; and a manufacturer's library.

A number of primary data were collected for each advertisement encountered. These primary data included product and manufacturer names, market sector, the journal in which the ad was found, the appearance date, and physical characteristics of the advertisement (number of pages, number of colors, location in the journal, ink bleed, and use of inserts). The number of pages and colors for each ad were recorded. Location in the journal was recorded as cover or "run of book." Bleed and inserts were recorded as yes or no. Coder reliability was assessed by conducting 50 spot checks during separate library visits, consulting a particular journal, inspecting a particular previously coded advertisement, and checking the accuracy of the original codes. Forty-eight of the checks proved to be clean, suggesting that the original coding was generally accurate with only minor errors.

A considerable amount of primary data was amassed-184 separate advertising appearances and 223 advertising pages for 23 different products. From the primary data, three voice measures were calculated-a count of the number of ads, a composite attention index, and a media cost estimate. Although competitive advertising reports exist for certain product categories, one was not identified at a reasonable cost for medical imaging equipment (Thompson Intermedia). Consequently, estimates of advertising spending that could be derived from the ads themselves were essential to estimate SOV. The simplest measure was to count the ads that appeared for each brand.

Previous comparative advertising research showed that advertising units of varying length, size, and physical appearance attributes could be compared employing a common yardstick. This research showed that in industrial advertising, an advertisement's size, its position in a journal, and its use of color, bleed, and inserts each contributed to the overall effect of the ad in capturing a reader's attention. Rossiter and Percy (1997, pp. 298-300) calculated these contributions and produced an index for each physical factor. Multiplying all factors present in a particular advertisement produces a composite "reader attention index score" for each advertising unit (Table 1). 
Every journal has its own advertising rate card. Typically, journals charge advertisers a basic rate, and then charge premiums for use of color, preferential positions within the journal, use of bleed, and use of an insert. The researchers consulted the rate card for each journal that included coded ads and obtained the applicable standard undiscounted September 2003 rates.

The focus of the analysis was to determine the principal communication channels employed for each market sector, how many competitors were using each channel, how strongly each competitor's messages were being transmitted, and to estimate the strength of each brand's "signal"-i.e., its share of voice. Separate analyses were conducted for product categories 1,2 , and 3.

\section{Analysis}

Product Category 1 Analysis

The collected data encompassed 89 separate advertising appearances and just under $\$ 0.5$ million in estimated media spending from eleven manufacturers over the course of the 12-month study period. The four major companies accounted for 59 ads and over $\$ 0.3$ million in spending or about two-thirds of the total. This category was the noisiest of all market sectors studied in this study. It was the leader in overall estimated advertising expenditure and comfortably second in most other SOV categories. Product 1 was also the most "creativeintensive" sector. Over twice as many unique ads appeared in support of these products than in any other category.

Brand A, the market leader, was the leading advertiser by all measures of this study (Table 3). It accounted for the most ad appearances, the most ad pages, and outspent its nearest competitor by nearly $50 \%$. Brand B was the second most prominent advertiser in the market. There is considerable concentration of voice in the marketplace. The top three competitors in each voice measure accounted for $50 \% \%$ or more of voice measures in this marketplace. Brand $\mathrm{C}$ was third among the four major brands (13\% to $17 \%$ of all voice measures) and was a minor player in this marketplace during the study period. The voice leader, Brand A, outspent Brand C in this category by a factor of 3.5 and Brand D by 4.5. As a result, Brand C and D's promotional messages were seriously diluted...

Among Brand C's product lines, this category contains the most competitors vying for purchaser attention. Brand $\mathrm{C}$ was using two of the three principal journals during the study period to support its product. Both journals were quite crowded and noisy, containing advertising for six to nine different competitive products. This volume of competitive product activity effectively diluted Brand C's placements in these journals. Brand $\mathrm{C}$ is a relative newcomer to the crowded Product Category 1. During the October 2002-September 2003 study period, Brand C held a relatively low share of voice in the observed advertising marketplace. Brand C's advertising efforts at that time were effectively "drowned out" by the large volume of competitive activity.

\section{Product Category 2 Analysis}

The collected Product Category 2 data encompassed 46 separate advertising appearances and almost $\$ 0.3$ million in estimated media spending from only four manufacturers over the course of the 12-month study period. This category was the quietest of all market sectors studied in this research. It was the last in all voice estimates: number of ads, attention index, and cost.

Brand C was the leading advertiser by all SOV measures of this study (Table 3). It accounted for the most ad appearances, the most ad pages, and outspent its nearest competitive advertiser (Brand A) by nearly 65\%. Brand $\mathrm{B}$ was the third most prominent advertiser in the market, followed by Brand $\mathrm{D}$, the market leader. There is considerable concentration of voice in this marketplace. With $44-52 \%$ of various voice measures, Brand C's promotional messages were relatively undiluted as a result of its advertising leadership position in the marketplace during the study period.

Among Brand C's product lines, this category is the only one in which it was the overall annual SOV leader among manufacturers in the marketplace. Since Brand $\mathrm{C}$ did not advertise uniformly throughout the year, 
Brand D managed to lead the market in SOV during the Fourth Quarter, a period in which Brand C's advertising was at its annual ebb. Brand $\mathrm{C}$ used the two principal journals during the study period to support its products. Brand $\mathrm{C}$ was one of four products advertised in the first journal, which contained advertisements for both Brands A and B. Brand C shared ad space in the second journal with advertisements for Brand D's product.

\section{Product Category 3 Analysis}

The collected Product Category 3 data encompassed 49 separate advertising appearances and almost $\$ 0.5$ million in estimated media spending over the course of the 12-month study period. The four major companies accounted for 41 ads and almost $\$ 0.4$ million in spending or about three-fourths of the total. This product category was the second "noisiest" of market sectors after Product Category 1.

Brand B was the leading advertiser by all SOV measures of this study. It accounted for the most ad appearances, the most ad pages, and marginally outspent Brand D. There is considerable concentration of voice in the marketplace. The top two competitors in each voice measure accounted for about $70 \%$ of voice measures in this marketplace.

The bulk of Brand C's observed advertising effort was applied to Model A. Brand C also executed a separate promotion for Model B. The principal journal used in Product Category 3 advertising in this study was relatively crowded, carrying ads from all four competitors. Brand $\mathrm{C}$ was the sole user of two other journals. During the October 2002-September 2003 study period, Brand C held a third-place SOV position in this market.

\section{Findings}

In Table 2, all measures (number of ads, attention index, and advertising cost) of SOV were expressed as percentages or proportions based on the four major competitors' measures. Analysis of variance was conducted within brand across the three SOV measures for each of the four brands in each of three product categories. Also, the proportions were subjected to an arc-sine transformation to achieve proportions with improved normality and homogeneity of variance characteristics (Milligan, 1987). Transformation of the proportions had very little effect on the statistical significance of the results reported in Table 2. The small $\mathrm{F}$ values and the high $\mathrm{p}$ values in the last two columns indicate that the ANOVA found no significance difference in the SOV measures for all brands in all product categories.

Consequently, for these four brands in these three product categories, it is not necessary to incur the time and expense to estimate SOV using attention adjustment factors or advertising rate cards. It is easier, quicker, less costly, and adequately reliable and valid to "just count the number of ads" placed in the journals. Therefore, in this market situation, the SOV measure will not affect the advertising budgeting decision.

Product Category 1 is problematic for Brand C. It has a large number of competitor companies as well as a large measure of competitive advertising activity. Brand $\mathrm{C}$ is charged with penetrating this market, yet its voice position in the marketplace during the study period was such that its advertising efforts were largely inconsequential — drowned out by a deluge of competitive activity. A substantial increase in advertising investment will be required to bring Brand $\mathrm{C}$ to a voice position in the marketplace so that its advertising effort would achieve notice above competitive noise. Product Category 2 is the one imaging market in which Brand $\mathrm{C}$ was in a strong voice leadership position over the course of the study period. Product Category 3 is a quiet market with few competitors and relatively little competitive activity. Brand C held a solid second in its SOV throughout the study period. 


\section{Advertising Budgeting Recommendations}

\section{Product Category 1}

The analysis indicates that Brand $\mathrm{C}$ has a SOV problem in this marketplace. Conventional wisdom suggests that Brand $\mathrm{C}$ needs to increase awareness of its product in the marketplace in order to achieve its market penetration goals. A logical solution would be for Brand C to purchase more SOV in the Product Category 1. For example, doubling its ad budget and appearances would place Brand $\mathrm{C}$ as a close third in SOV after Brands A and $\mathrm{B}$, making Brand C less likely to be overlooked. However, if the model in Figure 1 is applied to guide the advertising budgeting decision, the recommendation differs from conventional wisdom. Brand $\mathrm{C}$ is a follower in the market and Brand A is the market leader. Furthermore, Brand A's SOV exceeds its SOM (Philips). Consequently, the recommendation for Brand $\mathrm{C}$ is to follow a niche strategy-retreat and focus Brand C's product and reduce ad spending. Instead of attempting to compete with Brands A and B across the board, it may be better for Brand $\mathrm{C}$ to focus its smaller ad budget on selected product models toward specific user segments. Once this focus of product, audience, and ad budget is determined, it may be beneficial to alter the configuration of Brand C's advertising units in order for the brand to stand out more in the crowd. The data suggest near-uniformity in Product Category 1 advertising as 1-page, 4-color, bleed, non-insert, and with run of book ad placement. Therefore, a black-and-white, bordered (non-bleed), multi-page insert for a specific Brand $\mathrm{C}$ model would stand out rather dramatically from other advertising. Brand C's creative team might explore some or all such alterations of the "standard" advertising configuration to obtain greater visual impact and greater SOV for the same advertising dollar. In addition, according to Figure 1, Brand A should maintain, Brand B should attack, and Brand D should follow a niche strategy, similar to what they appear to be doing and in accordance with competitive marketing strategy recommendations.

\section{Product Category 2}

Brand $\mathrm{C}$ has no SOV problem in this marketplace. It dominates the market leader, Brand $\mathrm{D}$, by over 4 to 1 in advertising expenditures. Following the budgeting strategy recommended in Figure 1, Brand B should be attacking the market leader with a SOV premium of 2 to 1 . Accordingly, Brand B may be overspending and can reduce its advertising expenditures in this product category to focus efforts in the other product categories. However, there is still opportunity for refinement. Since the data suggest near-uniformity in advertising in this category similar to the previous category, the creative team might again explore alterations of the "standard" advertising configuration to obtain greater visual impact and attention. Since Brand D's SOV is considerably less than its SOM (10-15\% versus 31\%) (City of Seattle; Philips Medical Systems), Figure 1 suggests that all three of its competitors should attack, not just Brand C. It appears that Brand A and B's advertising efforts have paid off with SOM equal to $28 \%$ for each brand.

\section{Product Category 3}

The study data suggest that Brand C holds a third-place SOV in the marketplace for Product Category 3. While Brand $\mathrm{C}$ might be tempted to purchase more SOV in this market, the strategy recommended in Figure 1 is not to attack the market leader, Brand B. Since Brand B's SOV is greater than its SOM, the budgeting recommendation to follow is a niche strategy. Brand D appears to be attacking, against the advice based on Figure 1. Consequently, Brand C strategy that calls for focus on specific products and segments and a reduction in spending may be a better budgeting option than one that increases advertising expenditures. Doubling Brand C's ad budget would close the relatively large gap between Brands B and C, but Brand C would still be in third place with respect to SOV. Once again, exploring alterations of the "standard" advertising configuration to obtain greater visual impact for the same advertising dollar is recommended.

\section{Conclusions}

The conclusions from this SOV study are twofold. First, in the medical imaging market, dominated by four major product manufacturers who advertise in a limited set of professional journals, complex or costly SOV estimates are not necessary. Simply counting the number of ads that appeared is a good estimate of the advertising 
weight in a market. However, if there are more and varied dominant players in the markets using a greater variety of advertising media, this conclusion may not be applicable.

Second, SOV (however measured) can be a useful input to advertising budgeting decisions, especially when SOV is compared to SOM. Given the first conclusion, SOV for the major competitors can be estimated quite easily. When compared to popular alternative measures that rely on elusive advertising frequency distributions, such as minimum effective frequency and effective reach, SOV can make a significant contribution to advertising budgeting decisions. In addition, although the Schroer model was applied to capital goods markets instead of consumer packaged goods markets and was used to compare budgeting strategies among different product categories instead of across local regional markets, it appears to offer useful guidance. The model can be used to assess the allocation of past advertising budgets and, if the products, competitors, and markets do not change drastically, it can provide suggested budgeting strategies for the next budget year.

\section{Limitations and Future Research}

This study does not represent a complete survey of all advertising in these respective marketplaces. Regional medical libraries did not retain a few of the targeted journals. Sometimes, individual issues were found to be missing from the library collections. Other times, the libraries themselves removed the advertising that was to be the subject of this study because it was not considered of sufficient "academic interest." These findings are only as good as the data upon which they are based. Since there were a number of missing data in the data set after completion of the fieldwork, these recommendations and conclusions must be regarded as preliminary and used with caution.

In reality, it is rare for advertising media to be purchased at "list prices." Ads are often discounted for multiple purchases, customer loyalty, or the whim of the sales representative. The net effect of using list prices is an overstatement of media cost. This overstatement would be particularly applicable to leading advertisers, since they would be principal beneficiaries of volume discounting from various journals.

Of course, the conclusions are limited to the products, advertising media, and time frame of this study. In addition, the SOV measures estimated in this study are not independent, as they all depend upon the number of ads placed in the selected journals. Furthermore, before this study, the advertising budgeting strategy model in Figure 1 had been applied only to mature, consumer-packaged goods marketed in regional markets. Some readers may take issue with the application of the model to business-to-business capital goods typical of those in medical imaging product categories.

Future research could replicate this study or extend it to expand the measures of SOV. Attempts should be made to obtain measures that are more independent and are applied to media choices that are not so restrictive. Furthermore, additional product categories can be studied to determine if the model in Figure 1 can be reasonably applied to market situations other than packaged-goods marketing.

Authors' note: The authors thank Andrei Mikhailitchenko and Bridget McGraw, graduate assistants at Cleveland State University, for their assistance in data collection.

\section{References}

1. City of Seattle (n.d.), Member of the Month. Retrieved January 7, 2004, from City of Seattle, Trade Development Alliance of Greater Seattle website: http://www.ci.seattle.wa.us/tda/member_month.htm

2. Findlay Publications (n.d.), "Advertising in a Recession," Marketing to Manufacturing: Why It Pays to Advertise, http://www.findlay.co.uk/Marketing/M2M/home.asp?M2M_ID=10

3. Jones, John P. (1990), “Ad Spending: Maintaining Market Share,” Harvard Business Review, 68(1), 38-42.

4. Kelley, Larry D. (1985), "Can Share of Voice Replace Effective Frequency?" Marketing \& Media Decisions, 20 (13), 98-99. 
5. Knight, Christopher M. (n.d.), "Understanding SOV (Share of Voice)," http://www.ezine-tips.com/listtips/list-business/20000302.shtml

6. Milligan, Glenn W. (1987), "The Use of the Arc-Sine Transformation in the Analysis of Variance," Educational and Psychological Measurement, 47, 563-573.

7. Philips (n.d.), Retrieved January 7, 2004, from Philips website: http://www.philips.com/Assets/Downloadablefile/pms_freek_knoet-1340.pdf

8. Philips Medical Systems (n.d.), Retrieved January 7, 2004, from Philips Medical Systems website: http://www.medical.philips.com/main/company/aboutus/facts/

9. $\quad$ Rossiter, John R. and Larry Percy (1997), Advertising Communications \& Promotion Management, $2^{\text {nd }}$ ed. McGraw-Hill, 1997.

10. Schroer, James C. (1990), “Ad Spending: Growing Market Share," Harvard Business Review, 68(1), 44-48.

11. Thomson Intermedia, PLC (n.d.). Competitive Advertising Report: ART Thumbnail Creatives for April2001 to June-2001. http://www.thomson-intermedia.com/pre/research/rpts/comp_advert_rpt.doc

12. Turk, Peter B. (1988), "Effective Frequency Report: Its Use and Evaluation by Major Agency Media Department Executives," Journal of Advertising Research, (April/May), 55-59.

Table 1 Attention Adjustments for Industrial Magazine Ads

\begin{tabular}{lc}
\hline \hline Adjustment Factor & Index \\
Size of ad & \\
\hline 2-page & 1.7 \\
1-page (standard) & 1.0 \\
2/3-page & 0.8 \\
1/2-page & 0.7 \\
1/3-page & 0.4 \\
Color of ad & 1.4 \\
\hline 4-color & 1.2 \\
2-color & 1.0 \\
Black and white (standard) & \\
Position in magazine & \\
\hline Cover (average of all three & \\
\hline
\end{tabular}

Cover (average of all three cover positions)

Bleed

Bleed

Non-bleed

Insert

Ad with insert

No insert (run-of-press ad)

Source: Adapted from Rossiter and Percy (1997, p. 299). 
Table 2 Share of Voice Estimates of Medical Equipment Advertising

\begin{tabular}{|c|c|c|c|c|c|c|}
\hline Brand & & $\begin{array}{l}\text { Number } \\
\text { of Ads }\end{array}$ & $\begin{array}{l}\text { Attention } \\
\text { Index }\end{array}$ & $\begin{array}{l}\text { Adv. } \\
\text { Cost (\$) }\end{array}$ & $\mathbf{F}$ & $\mathbf{p}$ \\
\hline \multicolumn{7}{|c|}{ Product Category 1} \\
\hline Brand A & $\begin{array}{l}\mathrm{Y}=\text { proportion } \\
\mathrm{Y}^{\prime}=\operatorname{arc}-\operatorname{sine}\left(\mathrm{Y}^{1 / 2}\right)\end{array}$ & $41.5 \%$ & $46.1 \%$ & $46.2 \%$ & $\begin{array}{l}.16 \\
.19\end{array}$ & $\begin{array}{l}.86 \\
.83\end{array}$ \\
\hline Brand B & $\begin{array}{l}\mathrm{Y} \\
\mathrm{Y}^{\prime}\end{array}$ & 28.3 & 24.1 & 30.1 & $\begin{array}{l}.01 \\
.01\end{array}$ & $\begin{array}{l}.99 \\
.99\end{array}$ \\
\hline Brand C & $\begin{array}{l}\mathrm{Y} \\
\mathrm{Y}^{\prime}\end{array}$ & 17.0 & 15.5 & 13.5 & $\begin{array}{l}.12 \\
.18\end{array}$ & $\begin{array}{l}.88 \\
.84\end{array}$ \\
\hline Brand D & $\begin{array}{l}\mathrm{Y} \\
\mathrm{Y}^{\prime}\end{array}$ & 13.2 & 14.2 & 10.2 & $\begin{array}{l}.04 \\
.04\end{array}$ & $\begin{array}{l}.96 \\
.96\end{array}$ \\
\hline \multicolumn{7}{|c|}{ Product Category 2} \\
\hline Brand A & $\begin{array}{l}\mathrm{Y}=\text { proportion } \\
\mathrm{Y}^{\prime}=\operatorname{arc}-\operatorname{sine}\left(\mathrm{Y}^{1 / 2}\right)\end{array}$ & $22.0 \%$ & $19.8 \%$ & $25.9 \%$ & $\begin{array}{l}.25 \\
.27\end{array}$ & $\begin{array}{l}.78 \\
.77\end{array}$ \\
\hline Brand B & $\begin{array}{l}\mathrm{Y} \\
\mathrm{Y}^{\prime}\end{array}$ & 13.0 & 14.6 & 20.4 & $\begin{array}{l}.52 \\
.53\end{array}$ & $\begin{array}{l}.59 \\
.59\end{array}$ \\
\hline Brand C & $\begin{array}{l}\mathrm{Y} \\
\mathrm{Y}^{\prime}\end{array}$ & 52.0 & 50.2 & 43.8 & $\begin{array}{l}.34 \\
.46\end{array}$ & $\begin{array}{l}.71 \\
.63\end{array}$ \\
\hline Brand D & $\begin{array}{l}\mathrm{Y} \\
\mathrm{Y}^{\prime}\end{array}$ & 13.0 & 15.4 & 9.9 & $\begin{array}{l}.31 \\
.33\end{array}$ & $\begin{array}{l}.73 \\
.72\end{array}$ \\
\hline \multicolumn{7}{|c|}{ Product Category 3} \\
\hline Brand A & $\begin{array}{l}Y=\text { proportion } \\
Y^{\prime}=\operatorname{arc}-\operatorname{sine}\left(\mathrm{Y}^{1 / 2}\right)\end{array}$ & $22.0 \%$ & $16.6 \%$ & $12.5 \%$ & $\begin{array}{l}.66 \\
.69\end{array}$ & $\begin{array}{l}.52 \\
.50\end{array}$ \\
\hline Brand B & $\begin{array}{l}\mathrm{Y} \\
\mathrm{Y}^{\prime}\end{array}$ & 46.3 & 43.5 & 37.5 & $\begin{array}{l}.34 \\
.40\end{array}$ & $\begin{array}{l}.71 \\
.67\end{array}$ \\
\hline Brand C & $\begin{array}{l}\mathrm{Y} \\
\mathrm{Y}^{\prime}\end{array}$ & 17.1 & 14.8 & 14.4 & $\begin{array}{l}.07 \\
.07\end{array}$ & $\begin{array}{l}.94 \\
.94\end{array}$ \\
\hline Brand D & $\begin{array}{l}\mathrm{Y} \\
\mathrm{Y}^{\prime}\end{array}$ & 14.6 & 24.8 & 35.6 & $\begin{array}{l}2.52 \\
2.66\end{array}$ & $\begin{array}{l}.09 \\
.07\end{array}$ \\
\hline
\end{tabular}


Figure 1 Budgeting Strategies: Largest Competitor's Advertising Spending And Market Share

\begin{tabular}{|l|c|c|}
\hline & \multicolumn{2}{|c|}{ Largest Competitor (LC) in Market } \\
\hline Our Brand's SOM & Low SOV/SOM(below 1.0) & $\begin{array}{c}\text { High SOV/SOM } \\
\text { (1.0 or higher) }\end{array}$ \\
\hline Follower & $\begin{array}{c}\text { Attack - with a large SOV premium, } \\
\text { approximately twice that of the LC, and } \\
\text { sustain it for a year or more. }\end{array}$ & $\begin{array}{c}\text { Follow Niche Strategy - retreat and focus, } \\
\text { reduce spending. }\end{array}$ \\
\hline Leader & Maintain - set our SOV/SOM at 1.0. & $\begin{array}{r}\text { Follow Defensive Strategy - increase spending } \\
\text { to match that of the LC. }\end{array}$ \\
\hline
\end{tabular}

Source: Adapted from Rossiter and Percy (1997, p. 42). 
Notes 